\title{
“Normales", “anormales", "renormalizadas".
}

\section{Mujeres excombatientes: fronteras difusas entre víctimas y victimarias}

\author{
Natalia Escobar Sabogal*
}

Este texto se propone indagar acerca de las violencias de género infringidas sobre mujeres excombatientes de las Fuerzas Armadas Revolucionarias de Colombia (FARG) y las Autodefensas Unidas de Colombia (AUG). Las reflexiones que se generan en este trabajo son producto de relatos que

\footnotetext{
* Magíster en Antropología Social y psicóloga. Investigadora y docente universitaria, con experiencia en trabajo social y comunitario con población vulnerable (víctimas de violencia sexual, mujeres y niños en situación de discapacidad, desplazamiento, desmovilización, reintegración y servidores públicos). Diplomada en Psicología Clínica y de la Salud. Ha participado en procesos de construcción de políticas públicas, procesos testimoniales sobre el conflicto armado con perspectiva de género, construcción y diseño metodológico de programas de evaluación, intervención, prevención y conocimiento del trabajo institucional en los ámbitos público y privado. Ha trabajado con población en diversas zonas del país (Cali, Jamundí, Medellín, Barranquilla, Santa Marta, Tame, La Guajira, Pasto, Remolino de Taminango, Mocoa, Valle de Sibundoy, Ibagué y Cundinamarca). Es investigadora de la Agencia Colombiana para la Reintegración y de Arte para la Paz; también ha realización contribuciones al programa Reintegración y Prevención al Reclutamiento. En la Universidad de La Sabana ha desarrollado experiencias de integración escolar de alumnos con limitación visual e inclusión social de mujeres con discapacidad. Ha participado en las siguientes investigaciones: Atención en Salud a Víctimas de Violencia Sexual, Construcción de Subjetividades Laborales, Desempleo Masculino, Integración Escolar y Empoderamiento de Personas con Limitación. Correo electrónico: Natalia.escobarsabogal@gmail.com
} 
emergieron en una experiencia testimonial sobre el conflicto armado con perspectiva de género, en el que participaron mujeres víctimas y mujeres excombatientes que habitan la ciudad ${ }^{1}$.

Las violencias de género que se identifican en sus relatos pueden ser inscritas en tres escenarios, comprendidos como espacios comunes y momentos específicos en sus repertorios de vida. Estos escenarios problematizan, en primer lugar, las representaciones sociales que recaen sobre ellas y, en segundo lugar, el continuo de violencias que atraviesa sus historias.

El primer escenario, nombrado socialmente como el "orden y la normalización”, es el lugar habitado antes de pertenecer a un grupo armado ilegal (GAI); el segundo escenario se inserta en el imaginario colectivo como el lugar de la anormalidad, de los otros deshumanizados y de la pertenencia a un GAI; el tercer escenario hace referencia no solo al lugar de llegada después de su paso por un GAI (esto es: el orden social), sino también a un lugar definido a partir de los procesos y políticas de desarme, desmovilización y reintegración (DDR), que en su trasfondo trae la idea de renormalizar a esos otros y convertirlos en "personas de bien".

Estos tres escenarios están permeados por violencias de género, a partir de las cuales se problematiza la idea del orden social, la dicotomía paz/guerra y, con ella, la división aparentemente clara entre víctimas y victimarios. Las reflexiones aquí planteadas no pretenden ocultar el dolor y la barbarie de la guerra; más bien proponen un debate en torno a la comprensión de esta en un contexto social y en un entramado cultural que de múltiples formas posibilita, aprueba y apropia la violencia como práctica naturalizada en las relaciones sociales.

1 Este proyecto se desarrolló entre julio y diciembre de 2009, en el marco del Programa de Atención al Proceso de Desmovilización y Reintegración en Bogotá, de la Secretaría Distrital de Gobierno, y fue coordinado por Camila Medina Arbeláez. 
Se propone, entonces, un debate que reconozca y escuche las voces de sujetos que en muchos casos han quedado silenciadas: las voces de las mujeres excombatientes, a través de la generación de procesos de construcción de memoria, aunque no solo de la memoria oficial sino también de otras formas de archivar el pasado, que permitan identificar y resignificar los marcos interpretativos en los que las mujeres han construido los relatos de la guerra y las violencias vividas en ella.

\section{Primer escenario: el orden social, la normalidad}

La concepción opuesta "orden/guerra" trae consigo la idea de dos espacios limitados de manera fija: el primero de ellos agrupa elementos de normalidad, bien y paz, que deben representarse en las instituciones como la familia, la escuela y la sociedad; en el segundo espacio está contenido aquello que es anormal, generador de violencia, es lo que está al margen de la ley. La familia es el primer escenario donde las mujeres excombatientes identifican violencias de género; allí sus relatos problematizan la concepción "orden/guerra". ¿Cuál es el orden social que habitaban?

En este primer escenario, las violencias de género se desarrollaron en contextos sociales propicios para la formación de tipos de familias y prácticas de socialización que produjeron factores de riesgo para la violencia. Las formas de configurar la familia y las relaciones sociales descritas se asociaron al abuso sexual, la violencia física, la violencia psicológica, la carencia de redes sociales de apoyo, la nulidad de la propia voz, junto con factores socioeconómicos como pocas oportunidades laborales, de formación académica y condiciones precarias de vivienda, alimentación y salud.

En las historias de vida de las mujeres excombatientes se hace evidente un contexto predominantemente machista. Las formas de violencia de género suelen estar naturalizadas y promueven ejercicios de poder, simbólicos y prácticos, aceptados en muchos casos por las mismas mujeres: 
Yo me fui [al GAI] cuando iba pa' los 11 años... Yo nunca tuve el respeto de mi familia. A la edad que tenía, 10 años, un tío abusó de mí. Pa’ mí, ese tío era como si hubiese sido mi papá... A él no le importaba arrumarme a correa con la chapa; tras de que abusaba de mí, no me respetaba. Ese fue un motivo que yo tomé pa' tomar esa decisión. Esa fue la decisión mía de irme pa’ donde no debía irme: el saber que no tenía el respeto de mi familia. ¿Qué más esperaba yo? A una persona de mi edad, ¿quién le podía dar trabajo? Nadie (mujer excombatiente de las FARG).

Mi infancia fue nada bonita. Mi mamá me dejó, cuando yo tenía ocho meses, al cuidado de mi papá, que era un hombre de campo, que se vio a gatas para cuidar una niña, que decidió hacer vida con otra mujer, que de ahí en adelante empezó una amargura para mí como niña. Mi papá se tenía que quedar en los potreros, o con una cuadrilla de trabajadores a organizar algún trabajo. En ese tiempo yo quedaba en manos de mi madrastra. A mí no me permitía llegar a la casa, yo tenía que quedarme en los corrales o en los establos mientras mi papá llegaba. Ella a mí no me dejaba acercarme a la cocina a comer. Guando mi papá se ausentaba por días, ella me dejaba en un establo durmiendo como un ternerito más. Había otro hermano, comíamos de la caridad de los vecinos; a veces nos daban la dormida, pero se metían en problemas con esta señora. Los años pasaron y en lugar de irle cogiendo un tipo de aprecio o cariño a la vida, al contrario, yo le preguntaba a Chuchito: "Bueno Chuchito, ¿cuál es el objetivo de que yo esté aquí? Una vez, recuerdo, que ella me dejó encerrada tres días en un cuarto que se llama "el cuarto de la herramienta"; allá había un potecito de Baygon y yo tenía como ocho años: yo me tomé un potecito de esos. Yo decía: "Aquí mirando el techo, sin comida, me dejó un vaso con agua...". Si yo me quejaba o algo, ella entraba y me golpeaba, y yo dije: "Pues acabemos con esto". Y me tomé el puchito que quedaba de Baygon. 
Con tan buena o tan mala suerte, diría buena suerte, que lo único que me dió fue un dolor de estomago, pero no logré acabar con mi vida. Le trataba de contar a mi papá y él me pegaba porque decía que yo era una embustera, que antes agradeciera lo que esta señora hacía. Mi papá me pegaba, pero cuando él se iba, ella me pegaba cual ping-pong (mujer excombatiente de las AUC).

En los relatos de las mujeres hay uno que hace referencia a la mujer como perteneciente al ámbito privado y al cuidado de la familia. Esta idea, basada en la división sexual del trabajo, se erige como barrera de acceso al derecho a la educación:

Querer estudiar... Yo le dije a mi papá, me dijo que listo, pero haciéndome la claridad de que las mujeres no deberíamos de estudiar si no lo necesario: aprender a leer y aprender a escribir, porque pues ¿para qué un diploma? Si las mujeres estábamos destinadas a ser amas de casa, a tener un esposo para cuidarlo y unos hijos para cuidarlos (mujer excombatiente de las AUG).

Con la premisa de que la violencia es un hecho propio de la guerra, las prácticas de exclusión, rechazo y maltrato que se desarrollan en el interior del hogar se normalizan como formas de relación validas. Esta invisibilización de las violencias cotidianas ha abierto campo a posiciones críticas que cuestionan las formas binarias de clasificar el mundo y, con ellas, de excluir y ejercer violencias sobre las mujeres.

Los estudios de género han aportado en esta comprensión, vía la visibilización de las diversas formas de violencia (Arango y Viveros, 2011; Unifem, 2009). El movimiento feminista ha generado aportes en relación con la politización de la vida privada, el cuerpo y la sexualidad, al igual que ha promovido una crítica que debate las concepciones del Estado moderno como "una organización social y política que se distingue de otras por el 
monopolio legítimo del uso de la violencia" (Wills, 2005, p. 50). Los estudios feministas "demuestran que, aun en las democracias más avanzadas, con Estados consolidados, la violencia sigue ejerciéndose entre ciudadanos, sin que los violentos sean penalizados [...] cuando su uso [la violencia] ocurre tras los cuatro muros del hogar" (Wills, 2005, p. 50).

Las violencias que las mujeres relatan en este primer escenario, en algunos casos terminan por convertirse en motivaciones de ingreso al GAI. Estos aspectos pueden desencadenar razones para abandonar el espacio de vulnerabilidad y violencia que les significa la familia:

En esos ires y venires de la finca al estudio empecé a escuchar que unos compañeritos, los más grandecitos, empezaron a hablar que había una gente que había llegado al pueblo con mucha plata, que tenían poder y que estaban dando trabajo y que estaban pagando muy bien, que no había problema si eran menores de edad; y claro, si están pagando mejor que aquí, yo me voy. Hicieron unas reuniones y me di cuenta que no era para jornalear ni para la cocina, sino que eran las Autodefensas [...] Yo salí de esa reunión creyéndome la superchica. Además dije: “`Para qué aguantar hambre en mi casa?, ¿para qué aguantar maltratos en mi casa? De pronto allá me paguen". Cuando nos empezaron a decir que íbamos a portar un uniforme y un arma empezó la fascinación, porque interpretaba que era sinónimo de poder, porque uno veía en la guerrilla esas muchachas que llegaban armadas y se hacia lo que ellas querían. Yo como opción de vida iba a enamorarme de un jornalero y tener 4, 5 , 6,7 muchachitos, yo no quería ser eso, yo quería ser alguien más (mujer excombatiente de las AUC).

Vale la pena aquí tomar el fragmento de un relato, que hace parte de una investigación periodística (Lara, 2000) que, pese al enfoque esencialista de las diferencias entre los géneros, recupera la voz de una mujer excombatiente del ELN y del M-19: 
[Acerca del ingreso al grupo], lo hacían para huir del maltrato familiar, de la persecución de los padrastros y del exceso de trabajo que les ponían en la casa. Algunas lo hacían también porque les atraía algún guerrillero o les llamaba la atención el poder que generaban las armas. En las FARC solo conocí a una sindicalista que estaba realmente convencida de la causa. Las demás eran campesinas que habían encontrado una solución para su vida (Lara, 2000, p. 66).

Ciertas violencias de género se dan en el interior del hogar y convierten a las mujeres en sujetos silenciados. Por ello, "la vía guerrillera o la paramilitar se ofrecen como un estilo de vida en el que pueden poner límite a ese abuso o cambiar su estatuto de víctima” (Ramírez, 2002, p. 101).

El panorama de las violencias de género en este primer escenario, permite señalar dos aspectos para el análisis: en primer lugar problematizan las concepciones fijas de los escenarios de violencia, en donde orden y guerra terminan trastocándose; por otro lado, en algunos casos las violencias cotidianas pueden convertirse en motivaciones de ingreso a un GAI, sin argumentar que entre las violencias y el ingreso al grupo hay una relación directamente proporcional.

\section{Segundo escenario: la guerra, la anormalidad}

La guerra, comprendida a partir del marco de interpretación binario heredado de la modernidad, demarca para los hombres el lugar del guerrero; en oposición, las mujeres están lejos de este espacio. Pese a que este pensamiento permea grandes sectores del contexto colombiano, las mujeres también han conformado este territorio (Ferro y Uribe, 2002; Lara, 2000; Londoño, 2005; Medina, 2008; Ramírez, 2002; Wills, 2005). "Se estima que cerca del $40 \%$ de las FARC-EP son mujeres" y se ha identificado participación en menor medida en los grupos paramilitares (Ferro y Uribe, 
2002): "Uno de cada diez combatientes paramilitares es mujer, mientras que la proporción en las guerrillas es cuatro de cada diez" (Medina, 2008).

¿Ofrece la vía de la guerra límites a las violencias de género? Este segundo escenario pretende revisar dos casos específicos y, a partir de sus relatos, explorar las características de las formas de la violencia de género en el paso por la guerra, como también algunas variantes en relación con el GAI. El primer relato hace referencia al caso de una mujer excombatiente de las FARC; en este, la violencia infringida sobre el cuerpo no se da en el interior de GAI, sino que es realizada por actores estatales. Surge, entonces, la pregunta por la categorización binaria de buenos y malos, en la que en un lado de la matriz esta el Estado y en el otro, los GAI:

Allá no me fue muy bien tampoco: cuando yo llevaba tres años y medio me dejé coger por el Ejército. No me cogieron por guerrillera, sino por civil, porque yo estaba haciendo un almuerzo en una casa. Llegaron los compañeros de la guerrilla por el almuerzo, luego llegó el Ejército; a ellos los mataron porque se enfrentaron, a los otros nos cogieron. Yo cuando estuve allá en esa casa teníamos un plan, que cuando llegara el Ejército yo hacerme pasar por familiar de la viejita. Cuando llegó el Ejercito, a mí me cogieron y me echaron pa'l monte; a unos se los llevaron heridos, a la excompañera mía también se la llevaron herida, pero ella estaba uniformada. Antes de matarla, abusaron de ella, que eran como 56-54 chulos. Al muchacho compañero le metieron un palo, lo volvieron nada, y a mi alcanzaron a pasar 34 por encima mío. A mí lo que me salvó fue el señor, el viejito de la casa, que estaba cortando la leña. Cuando llegó el viejito, la viejita estaba amarrada. El viejito desamarró a la señora, cogió la yegua, se fue al pueblo y trajo toda la población. Por esa gente es que a mí no me mataron, porque a mí me iban a matar. A mí cuando me estaban violando, todo el mundo decía: "Ay, jueputa, ¿cómo sí le da cuca a los guerrilleros? Entonces toca que nos dé a nosotros también". Y yo estoy viva es de milagro, porque esa 
gente me iba era a matar a mí, para no dejar huellas de lo que habían hecho (mujer excombatiente de las FARG).

En este relato se narra el cuerpo de la mujer como lugar receptor directo de violencia, la violación como un arma de guerra y el cuerpo femenino como un escenario donde se disputa el poder:

La violencia sexual contra las mujeres se trata de una práctica aceptada por la tácita tradición entre ejércitos conquistadores para afectar el honor masculino, humillarle y enrostrárselo como victoria para desmoralizarlo por no haber podido proteger a sus mujeres (Velásquez, 2001, p., 24).

Las categorías que identifican a la guerra como el espacio de la violencia y al Estado como protector se trastocan; la mujer excombatiente percibe la guerra como su lugar de protección y, por el contrario, experimenta la violencia por parte del Estado. ¿Indica esto que no hay violencias de género en el interior de los GAI? Pese a que en los relatos trabajados no se encontró casos de violación en el interior de estos, sí se han identificado otras formas de control del cuerpo, de la sexualidad y de las relaciones de pareja, que suelen ser naturalizadas y no percibidas como violencias (Medina, 2008).

Este factor está mediado por la percepción que tienen las mujeres acerca de la reivindicación de los lugares ocupados antes del ingreso al GAI: el salir de un contexto permeado de violencias hacia uno donde encuentran posibilidades de elección y mayor control en relación con la violencia sexual. Vale la pena resaltar también que pese al carácter discursivo de la igualdad en los grupos guerrilleros, se encuentra una tensión entre esta y las prácticas de exclusión basadas en el género en el grupo (Medina, 2008).

Mientras que en el primer escenario las violencias se viven en el interior del hogar y quedan silenciadas por el carácter privado que connotan, en el GAI (las FARC, en este caso) hay una serie de transformaciones: las mujeres 
perciben una forma de empoderamiento, de ganancia, en el sentido de ocupar un lugar, y encuentran en la normalización y la regulación una forma de organizar su vida al interior del GAI. Aun así, esta regulación suele ser un factor que desencadena prácticas de violencia de género.

El un segundo relato, una mujer excombatiente de las AUC evidencia situaciones de control sobre el cuerpo, la sexualidad y la natalidad. Aunque vale la pena mencionar que en las AUG hay controles y restricciones en menor grado, hay un abanico de posibilidades más amplio en relación con la sexualidad de las mujeres. El aborto no es una política institucionalizada, pues depende y varía según el lugar y el comandante (Medina, 2008):

Los embarazos en los grupos armados son prohibidos, ameritan sanciones. Yo vi en el grupo que muchachas quedaban embarazabas y lo decían o se dejaban pillar, y las sacaban. Decían que las iban a llevar a trabajar de urbanas o inteligencia, pero no, las sacaban era a abortar. Les importaba un pepino si se moría o no la muchacha, y yo no quería que pasara eso, yo quería darme el lujo de tener una barriga, de tener un hijo. Oculté el embarazo hasta los siete meses, fajándome, utilizando uniformes más grandes. La barriguita de uno no iba hacia adelante sino hacia un lado; ipor Dios!, crecía como debajo del pulmón. A los siete meses informé; gracias a Dios muchas cosas pasaron para que tomaran la decisión de sacarme del sector, me llevaron a una ciudad a trabajar. En el embarazo, para no dar señas de que estaba embarazada, no me podía dar el lujo de un mareo, un antojo. Había palabras que para mí eran prohibidas como decir: "Ay, estoy antojada de comer algo", porque enseguida todo el mundo: "Uyyyy, ¿cómo así?”. Trabajar común y corriente, porque yo no podía decir: "No, es que estoy embarazada, y no puedo hacer una chamba o una trinchera, o no puedo prestar guardia tantas horas de pie, o no puedo ir a traer agua o leña". No, de malas, me tocaba, yo quería tener ese bebé, yo quería que naciera. Trabajaba igual; ahí trabajé hasta que tuve el bebé. Me dieron permiso de estar 
con él seis meses, y de ahí en adelante debía presentarme, luchar allá, dejar el niño a cuidado de alguien. Llegué a pedir la baja y no me la dieron: para ingresar usted tiene las puertas abiertas, pero que eso no era una finca de recreo, me dijo el comando (mujer excombatiente de las $\mathrm{AUC})$.

\section{Tercer escenario: renormalización}

Cuando las mujeres excombatientes abandonan el GAI, ¿a qué tipo de orden social ingresan y qué implica la reintegración? En este tercer escenario, sus historias evidencian formas de violencia durante el proceso de reintegración y a partir de la imposición del nombre "excombatiente". Con este calificativo se impone también toda una carga representacional y simbólica, que genera un lugar de exclusión en el que las mujeres están constantemente ocultando su vivencia en la guerra, para evitar nuevas formas de violencia.

Sus relatos no señalan aspectos específicos en relación con las violencias de género, pero el proceso de reintegración se da en un contexto en el que los roles de género siguen estando diferenciados y en el que ser hombre desmovilizado tiene una mayor aceptación, pero ser mujer desmovilizada no solo atenta contra la idea de orden, sino que además atenta contra los roles sociales establecidos para la mujer (pasiva, tierna, sumisa, débil).

Una de las formas de violencia que narran las mujeres se relaciona con los procesos de estigmatización que recaen a partir de la imposición del nombre "excombatiente":

En un colegio, en un conversatorio, los muchachos del colegio no sabían de qué era. Comienza mi compañero y dice: "¿Ustedes saben algo de los desmovilizados, qué son, qué son los reintegrados?". Uno decía una cosa, el otro otra: no, que son asesinos, son unos hijueputas, ellos han matado, ellos han desplazado, han hecho mucho daño. Siguió el 
compañero con la presentación: “¿Ustedes a un desmovilizado le darían las llaves de su casa?". No, que ni porque estuvieran locos, que como así, que para nada. Otra pregunta: "Si ustedes supieran que la persona que está al lado sentada es un desmovilizado, ¿ustedes qué harían?”. Dijo una muchacha: "Yo salgo corriendo, en qué momento saca una pistola y me mata". Yo estaba sentada con esos muchachos. Mi compañero dijo: "Mucho gusto, mi nombre es fulanito de tal y soy desmovilizado". Y yo dije: "Mucho gusto, soy desmovilizada de las AUC". Y todos quedaron como ahhh, trágame tierra. Los desmovilizados son para la sociedad sinónimo de maldad, de asesinos, de ladrones, de viciosos, de todo, nada bueno (mujer excombatiente de las AUG).

Se identifican además dos ámbitos en los que se generan prácticas de violencia: el educativo y la cotidianidad de la vivienda. Estos espacios normalizan los procesos de exclusión, de segregación, distinción de grupos por estereotipos y estigmatización:

En los colegios, pues sí, hay mucha discriminación sobre el hecho de que somos desmovilizados y por parte de los profesores, porque ellos mismos se encargan de divulgar. Porque, por ejemplo, uno llega, yo llegué a estudiar y tranquilita todo normal con los otros, uno trata de relacionarse con los otros y ¿cómo es que el profesor llama?: "Por favor, todos los de la Alta Consejería acá”. ¿Y los que no saben nada qué? Yo me quedé como... ¿`será que paso o espero? Y unos tipos decían: “¿Eso de la Alta Consejería que será? Y yo mmm, ni idea, me quedé, hice tiempo, esperé hasta que todos se fueran. Ay, Dios mío, yo tengo que firmar, pero pues no quería que se enteraran; entonces hasta que el profesor ya se iba a ir, le dije: "Profe, es que yo falto por firmar”. "¿Pero usted porqué no firmó?". "“..Profe, no nos boleté así tan feamente"... Imagínese yo bien tranquila y unos papacitos ahí viendo, no, por favor... y justo uno me pregunta: “¿Eso qué es?”. Y yo: “Ni idea”. Fue lo primero que se me ocurrió. No hombre, qué va, imagínese que sepa que 
yo soy desmovilizada; por eso es que empiezan a discriminar y a mirar así como que ahhhh. Eso me pasó en un curso. Estábamos con muchachos; ellos eran queridos con uno, chéveres, pero cuando se enteraron que era desmovilizada, nos dejaron a todos los desmovilizados juntos y entonces uno siente como rechazo (mujer excombatiente de las AUC).

Imagínese, donde vivo, si se enteran que soy desmovilizada, me echan de una. Imagínese, mi vecina un día, viendo las noticias, dijo: "No, eso es una plaga, eso sinceramente debieran de hacer lo que hicieron en Ecuador, que quemaron los colombianos vivos. El que es nunca deja de ser". Yo nada más la miraba: "Sííí, tiene toda la razón; terrible, ¿no?”. Y me fui yendo. Esa señora se llega a dar cuenta, me quema viva. Yo la escucho: "Es que los desmovilizados son la plaga". Yo nada más la veo, y una vez no más le dije: "Los desmovilizados son personas como cualquiera, simplemente que todos tenemos una historia”. Y ella dijo: “Usted por qué es que los defiende tanto?”. "No, yo no estoy defendiendo a nadie, solo digo, pues respeto". Mmm, se llegan a enterar que soy desmovilizada y, primero que todo, me echan y mi vecina me quema viva. Yo sí trato de que nadie se entere; la gente lo discrimina a uno mucho. Yo he sufrido por ese lado: por la discriminación yo vivía en una parte y me tuve que mudar; vivía con esa sensación maluca de que te miran feo, el susurro cuando uno entraba y todo eso (mujer excombatiente de las AUC).

Sus historias en general narran la dificultad de pertenecer a un contexto que les pide abandonar las armas, pero que excluye cuando lo hacen e intentan ingresar de nuevo al orden social:

Con los desmovilizados hay una discriminación terrible. Con decirle que usted va a pedir trabajo en una parte y sepan que es desmovilizado, vea... Uno tiene que ocultar la identidad, las mismas psicólogas le dicen a uno que no diga que es desmovilizado. Yo estuve en un taller de 
derechos, yo pleiteaba de que nosotros no teníamos por qué ocultarlo, si somos desmovilizados, somos desmovilizados; si de pronto perjudicamos a la gente no es culpa de uno; no tiene por qué negarse ni escondernos, porque existimos. En una localidad tenemos que hacernos ver, que sí existimos, que somos personas que queremos trabajar y que queremos salir adelante; no tenemos que escondernos, porque entonces ¿cuándo vamos a salir para tener nosotros ese derecho? (mujer excombatiente de las FARG).

\section{Notas finales para la reflexión}

"Salí de sufrir pa' seguir sufriendo", dice una mujer excombatiente de las FARC. A partir de la identificación de este continuo de violencias de género, se problematiza la dicotomía víctima/victimario y, con ella, todas las que producen los conceptos y comprensiones de la guerra, que permean no solo el sentido común, sino también las políticas de desarme, desmovilización y reintegración que se desarrollan en Colombia.

En cuanto a la construcción de memoria y conocimiento, los relatos de las mujeres plantean retos a la hora de indagar las relaciones entre orden y conflicto: ¿cuál es el entramado cultural y de qué formas valida la guerra? ¿Qué alternativas se deben construir ante pensamiento dicotómico y estático?

Las reflexiones aquí planteadas, más que intentar concluir y enunciar verdades fijas, persiguen abrir un debate que posibilite la comprensión de los procesos violentos, las formas en que se naturalizan, las maneras de nombrar a los otros, las líneas divisorias entre el orden social y la guerra y, finalmente, repensar las concepciones que subyacen a las políticas que se construyen en torno al proceso de paz en un país donde el conflicto aún sigue en pie. 


\section{Referencias}

Arango, L. G. y Viveros, M. (2011). El género: una categoría útil para las ciencias sociales. Bogotá: Universidad Nacional de Colombia.

Lara, P. (2000). Las mujeres y la guerra. Bogotá: Planeta.

Londoño, M. (2005). La corporalidad de las guerreras: una mirada sobre las mujeres combatientes desde el cuerpo y el lenguaje. Revista de Estudios Sociales, 21, 67-74.

Ferro, J. G. y Uribe, G. (2002). El orden la de guerra. Las FARC-EP: entre la organización y la política. Bogotá: Centro Editorial Javeriano.

Medina, C. (2008). "No porque seas paraco o seas guerrillero tienes que ser un animal". Procesos de socialización en FARC-EP, ELN y grupos paramilitares (1996-2006). Bogotá: Universidad de los Andes.

Ramírez, M. E. (2002). Las mujeres y la guerra. Psicología desde el Caribe, 9, 89-124. Universidad del Norte.

Velásquez, M. (2001). Reflexiones sobre el conflicto armado colombiano desde una mirada feminista. Otras Palabras, 8 , 17-32.

Wills, M. E. (2005). Historia, memoria, género: trayectoria de una iniciativa y aprendizajes. En Unifem. ¿fusticia desigual? Género y derechos de las víctimas en Colombia (pp. 41-81). Bogotá: Fondo de desarrollo de las Naciones Unidas para la Mujer. 